\title{
Inhibition of STAT3 signaling as critical molecular event in resveratrol-suppressed ovarian cancer cells
}

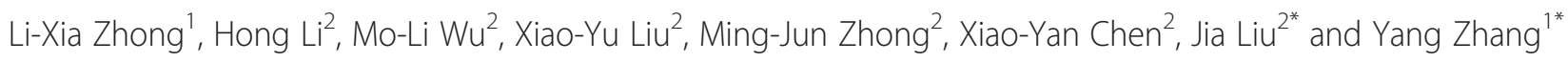

\begin{abstract}
Background: Resveratrol exerts inhibitory effects on ovarian cancer cells, while its underlying mechanism and critical molecular target(s) have been lesser known. Activations of Wnt, Notch and STAT3 signaling are frequent in ovarian cancers/OCs and supposed to be important for OC formation and progression, while the impacts of resveratrol on these signaling pathways in OC cells remain obscure.

Methods: In this study, two human ovarian cancer cell lines, OVCAR-3 and CAOV-3, were treated by $120 \mu \mathrm{M}$ resveratrol and their responses to the treatment and the statuses of Wnt, Notch and STAT3 signaling in them were analyzed by multiple experimental approaches. Selective inhibitors of Wnt, Notch or STAT3 signaling were employed to treat OVCAR-3 and CAOV-3 cells to elucidate the significance of individual signaling pathways for ovarian cancers.
\end{abstract}

Results: The results demonstrated distinct inhibitory effects of resveratrol on human ovarian cancer cells in terms of remarkable G1 phase accumulation, increased apoptosis fraction and concurrent suppression of Wnt, Notch and STAT3 signaling as well as their downstream cancer-related gene expression. Treatments with Wnt, Notch or STAT3 selective inhibitor revealed that only AG490, a JAK-specific inhibitor, inhibits OVCAR-3 and CAOV-3 cells in the extent as similar as that of resveratrol.

Conclusion: Our results suggest the significance of STAT3 activation in the maintenance and survival of ovarian cancer cells. The activated STAT3 signaling is the critical molecular target of resveratrol. Resveratrol would be a promising candidate in the management of ovarian cancers, especially the ones with resistance to conventional therapeutic agents.

Keywords: Ovarian cancer, Resveratrol, Signal transduction pathway, STAT3, Selective inhibitor, Gene expression

\section{Introduction}

Ovarian cancer (OC) is one of the commonest female malignancies and accounts for the leading death rates among the gynecologic cancers [1,2]. The main reasons of the poor prognosis of OCs are the delayed diagnosis due to the very subtle symptoms at the early stage of ovarian carcinogenesis [3] and the easiness of spreading through blood dissemination [4] and peritoneal transplantation [5,6]. Surgical treatment is the first choice to remove ovarian cancers if the tumours are well-differentiated, in relative small

\footnotetext{
* Correspondence: jialiudl@aliyun.com; yangzhangdl@126.com

${ }^{2}$ Liaoning Laboratory of Cancer Genetics and Epigenetics and Department of Cell Biology, Dalian Medical University, Dalian 116044, China

'Department of Clinical Oncology, Second Affiliated Hospital of Dalian

Medical University, Dalian 110042, China
}

sizes and/or confined to the ovary $[7,8]$. However, the patients with advanced OCs have to be operated for debulking the disease and then treated by standard chemotherapy such as a dose-dense paclitaxel and carboplatin regimen $[9,10]$. Although the therapeutic outcome has been improved by more accurate staging of the disease and more aggressive surgical excision of tumor spots in the abdomen, the overall survival rates remain unoptimistic because of the frequent tumour recurrence and severe toxic effects of the anticancer agents [11-13]. For these reasons, it would be necessary to explore more efficient and lesser toxic agent(s) with clearer molecular targets for better adjuvant management of ovarian cancers. 
Resveratrol (3,5,4'-trihydroxy-trans-stilbene) has been regarded as a non-toxic polyphenolic compound that can be found in grapes, berries, peanuts and red wine [14]. A body of evidence has demonstrated that resveratrol is able to inhibit the growth of many cancers such as bladder cancer, breast cancer and primary brain tumors [15-17]. Increasing data have shown that resveratrol can exert its biological effects on cancer cells by altering multiple molecular targets $[18,19]$. For example, it suppresses growth and induces apoptosis of human medulloblastoma cells accompanied with inhibition of STAT3 activation and transcription [18]. More importantly, the anticancer doses $(100 \mu \mathrm{M}$ to $200 \mu \mathrm{M})$ of resveratrol have little harmful effect on glial cells and neurons in central nervous system and transitional epithelial cells of the urinary bladder $[15,17,19]$. The inhibitory effects of resveratrol on ovarian cancer cells have been documented as well $[20,21]$. Although some studies have shown certain molecular alterations in resveratrol-treated ovarian cancer cells, such as down-regulation of Akt/GSK signaling [22] and VEGF expression [23], the critical event(s) among those alterations remains largely unknown. It is therefore necessary to address this point by comprehensively analyzing the statuses of ovarian cancer-related signaling pathways as well as their downstream genes.

Some signaling transduction pathways are found to be activated in the processes of ovarian carcinogenesis and play favorable roles in cell growth and survival [24-26]. For instance, hyperactive Jaks/STAT3 signaling promote enhanced colony-forming ability, motility and migration of cisplatin-resistant ovarian cancer cells [27]. Similarly, Wnt/beta-catenin pathway also contributes to the proliferation of human ovarian cancer cell [28] and inhibition of Notch signaling, a key pathway for ovarian cancer stem cells, sensitizes tumors to platinum therapy [25]. The data obtained from other cancer systems reveal that resveratrol can inhibit the signaling pathways mediated by STAT3, Wnt and Notch when exerting its cancer suppressive effects $[18,29,30]$. The current study thus refers to the above findings as a cue and/or a cutting edge to identify the critical molecular event(s) caused by resveratrol in ovarian cancer cells.

\section{Materials and methods}

\section{Cell culture and treatment}

Human ovarian cancer CAOV-3 cells [31] were cultured in Dulbecco's modified Eagle's essential medium (DMEM) containing $12 \%$ fetal bovine serum (Gibco Life Science, Grand Island, NY, USA) under $37^{\circ} \mathrm{C}$ and $5 \% \mathrm{CO}_{2}$ condition and OVCAR-3 cells [32] in Roswell Park Memorial Institute 1640 Medium (RPMI1640) under $37^{\circ} \mathrm{C}$ and $5 \%$ $\mathrm{CO}_{2}$ condition. The cells $\left(5 \times 10^{4} / \mathrm{ml}\right)$ were plated to culture dishes (NUNC, Denmark) and incubated for $24 \mathrm{~h}$ before the experiments. Meanwhile, dozens of cell-bearing coverslips were concurrently prepared using the NestDishes (Nest Biotech. Inc., Wuxi, China; China invention patent No. ZL200610047607.8); they were collected from Nest-Dishes, incubated under different experimental conditions and then harvested for H/E morphological staining, immunocytochemical (ICC) labeling and TUNEL assay. Resveratrol (Res; Sigma Chemical, Inc, St. Louis, MO, USA) was dissolved in dimethylsulfoxide (DMSO; Sigma) and diluted with culture medium to the working concentrations just before use. The cells were treated by $100 \mu \mathrm{M}[16,18,19]$ or $120 \mu \mathrm{M}$ Res for 72 hours. The normally cultured cells and the cells treated by $0.2 \%$ DMSO were used as normal and background controls, respectively. Cell numbers and viabilities were checked in $24 \mathrm{~h}$ intervals. The experimental groups were set in triplicate and the experiments were repeated at least for three times to establish confidential conclusion.

\section{Evaluation of cell growth}

The effects of resveratrol on cell proliferation were determined by 3-[4,5-Dimethylthiazol-2-yl]-2,5-diphenyltetrazolium bromide (MTT) assay [17]. The results were shown as percentage of cell viability (OD of the experiment samples/OD of control) or OD values. And the fractions of viable and unviable cells in normally cultured and resveratrol-treated populations were estimated with cell counting apparatus (TC20 Automated Cell Counter, BIO-RAD Inc., Singapore). Terminal deoxynucleotide transferase (TdT)-mediated dUTP-biotin nick-end labeling (TUNEL) assay was employed to detect apoptotic cells according to producer's instructions (Promega Corporation, USA). Haematoxylin and eosin (H/E) staining was performed on the three groups of OVCAR-3 and CAOV-3 cells to evaluate their morphological features.

\section{Flow cytometry}

The harvested cells of the experimental groups were fixed in 70\% ethanol for staining with DNA dye, and then suspended in $0.5 \mathrm{ml}$ to $1 \mathrm{ml}$ of propidium iodide solution containing RNase and incubated at $37^{\circ} \mathrm{C}$ for 30 minutes. Cell cycle profiles and cell apoptotic fractionations were obtained with a FACSvantage flow cytometer (Becton Dickinson, San Jose, CA, USA) and the data were analyzed with ModFit software (Verity Software House, Inc, Topsham, $\mathrm{ME})$. The analyses were repeated for three times to establish confidential conclusion.

\section{Immunocytochemical staining}

Immunocytochemical staining (ICC) was performed on the cell-bearing coverslips of the three experimental groups by the method described previously [18]. The antibodies against human STAT3, p-STAT3, Notch1, Notch2, HES1, Wnt2, $\beta$-catenin, E-cadherin, Bcl-2, c-Myc, survivn were purchased from Santa Cruz Biotechnology, Inc, CA and 
HES1 was provided by Dr. Tetsuo Sudo as a generous gift [29]. Color reaction was developed using 3, 3'-diaminobenzidine tetrahydrochloride (DAB). According to the labeling intensity, the staining results were evaluated by two independent researchers and scored as negative $(-)$ if no immunolabeling was observed in target cells, weakly positive $(+)$ if the labeling was faint, moderately positive $(++)$, and strongly positive $(>++)$ when the labeling was stronger or distinctly stronger than $(++)$.

\section{RNA isolation and RT-PCR}

Sample RNAs were isolated from the two ovarian cancer cell lines cultured under different conditions for 48 hours using Trizol solution (Life Technologies, Grand Island, NY, USA). By the method described elsewhere [8], reverse transcription (RT) was performed on RNA samples, followed by polymerase chain reaction (PCR) with a pair of primers specific for the cDNA of an individual gene (Table 1). The PCR products were resolved on $1 \%$ agarose gel containing ethidium bromide $(0.5 \mu \mathrm{g} / \mathrm{ml})$, visualized and photographed using UVP Biospectrum Imaging System (UVP, Inc, Upland, CA). The $\beta$-actin PCR products generated from the same RT solution were cited as quantitative controls.

\section{Protein preparation and Western blotting}

Total cellular proteins were prepared from the cells under different culture conditions. The sample proteins $(50 \mu \mathrm{g} / \mathrm{well})$ were separated in $10 \%$ sodium dodecylsulfate-polyacrylamide gel electrophoresis and transferred to polyvinylidene difluoride membrane (Amersham, Buckinghamshire, UK). The membrane was blocked with 5\% skimmed milk in TBS-T (10 mM Tris-HCl, pH8.0, $150 \mathrm{mM} \mathrm{NaCl}$ and 0.5\% Tween 20 ) at $4^{\circ} \mathrm{C}$, rinsed 10 minutes for three times with TBS-T, followed by $3 \mathrm{~h}$ incubation at room temperature with the first antibody in appropriate concentrations (Notch1: 1:800; Notch2: 1:800; Hes1: 1:2500; Wnt2: 1:800; $\beta$-catenin: 1:800; E-cadherin: 1:600; STAT3: 1:800; Bcl-2: 1:800; c-Myc: 1:600; survivin: 1:800), and then $1 \mathrm{~h}$ incubation with HRPconjugated anti-mouse or anti-rabbit IgG (Zymed Lab, Inc). The bound antibody was detected using the enhanced chemiluminescence system (Roche $\mathrm{GmbH}$, Mannheim, Germany). After removing the labeling signal by incubation with stripping buffer [8], the membrane was reprobed with other antibodies one by one until all of the parameters were examined.

\section{Selective inhibition of activated Wnt, Notch and STAT3 signaling}

L-685,458 (Calbiochem, San Diego, CA) is a potent and selective $\gamma$-secretase inhibitor, which inhibits Notch activation [33]. XAV-939 (Selleck, Houston, Texas, USA) selectively suppresses the transcription of $\mathrm{Wnt} / \beta$-catenin through inhibiting tankyrase1/2 [34]. AG490 (Sigma, Inc,
Table 1 Sequences of RT-PCR Primers and their generated product

\begin{tabular}{|c|c|c|c|}
\hline Parameters & Primer sequences & $\begin{array}{l}\text { Product } \\
\text { size (bp) }\end{array}$ & Reference \\
\hline \multirow[t]{2}{*}{$\overline{\text { Notch1 }}$} & $\begin{array}{l}\text { F:5' - TGT GAC AGC CAG } \\
\text { TGC AAC TC - } 3^{\prime}\end{array}$ & 577 & {$[29]$} \\
\hline & $\begin{array}{l}\text { R:5' - TGG CAC TCT GGA } \\
\text { AGC ACT GC - 3' }\end{array}$ & & \\
\hline \multirow[t]{2}{*}{ Notch2 } & $\begin{array}{l}\text { F:5'-AAT GTC ATG GCC GCT } \\
\text { TCA GAG-3' }\end{array}$ & 533 & [29] \\
\hline & $\begin{array}{l}\text { R:5'-TCG TGC AAG AGC } \\
\text { CAG TTA CCC-3' }\end{array}$ & & \\
\hline \multirow[t]{2}{*}{ Hes1 } & $\begin{array}{l}\text { F:5' - CCA GTT TGC TTा } \\
\text { CCT CAT TCC - } 3^{\prime}\end{array}$ & 240 & [29] \\
\hline & $\begin{array}{l}\text { R:5' - TCT TCT CTC CCA } \\
\text { GTA TTC AAG TTC C - } 3^{\prime}\end{array}$ & & \\
\hline \multirow[t]{2}{*}{ Wnt2 } & $\begin{array}{l}\text { F:5' - GCC ACA CGC TGC } \\
\text { ACC TAA AGC - 3' }\end{array}$ & 379 & {$[30]$} \\
\hline & $\begin{array}{l}\text { R:5' - CAA TTA CCC TAA } \\
\text { GGG TGG TAG C - 3' }\end{array}$ & & \\
\hline \multirow[t]{2}{*}{$\beta$-catenin } & $\begin{array}{l}\text { F:5'-TGA TGG AGT TGG } \\
\text { ACA TGG CCA TGG-3' }\end{array}$ & 570 & [53] \\
\hline & $\begin{array}{l}\text { R:5'-CAG ACA CCA TCT } \\
\text { GAG GAG AAC GCA-3' }\end{array}$ & & \\
\hline \multirow[t]{2}{*}{ E-cadherin } & $\begin{array}{l}\text { F:5'-GAC GCG GAC GAT } \\
\text { GAT GTG AAC-3' }\end{array}$ & 281 & [30] \\
\hline & $\begin{array}{l}\text { R:5'- TTG TAC GTG GTG } \\
\text { GGA TTG AAG A-3' }\end{array}$ & & \\
\hline \multirow[t]{2}{*}{ STAT3 } & $\begin{array}{l}\text { F:5- GGG TGG AGA AGG } \\
\text { ACA TCA GCG GTA A-3' }\end{array}$ & 298 & {$[15]$} \\
\hline & $\begin{array}{l}\text { R:5'- GCC GAC AAT ACT } \\
\text { TTC CGA ATG C - } 3^{\prime}\end{array}$ & & \\
\hline \multirow[t]{2}{*}{ survivin } & $\begin{array}{l}\text { F:5'-GGC ATG GGT GCC } \\
\text { CCG ACG TTG-3' }\end{array}$ & 439 & {$[15]$} \\
\hline & $\begin{array}{l}\text { R:5'-CAG AGG CCT CAA } \\
\text { TCC ATG GCA-3' }\end{array}$ & & \\
\hline \multirow[t]{2}{*}{ c-Myc } & $\begin{array}{l}\text { F:5'-TGG TCT TCC CCT } \\
\text { ACC CTC TCA AC - -3' }\end{array}$ & 265 & [15] \\
\hline & $\begin{array}{l}\text { R:5'-GAT CCA GAC TCT } \\
\text { GAC CTT TTG CC -3' }\end{array}$ & & \\
\hline \multirow[t]{2}{*}{$\mathrm{BCl}-2$} & $\begin{array}{l}\mathrm{F}: 5^{\prime}-T \pi T \text { GAG TTC GGT } \\
\text { GGG GTC AT }-3^{\prime}\end{array}$ & 275 & {$[54]$} \\
\hline & $\begin{array}{l}\text { R:5'-TGA CTT CAC TTG } \\
\text { TGG CCC AG -3' }\end{array}$ & & \\
\hline
\end{tabular}

St. Louis, MO), a JAK-specific inhibitor, can suppress STAT3 signaling by inhibiting Tyr705 phosphorylation of STAT3 protein [19]. To evaluate the importance of the three signalling pathways in the growth and survival of ovarian cancer cells, CAOV-3 and OVCAR-3 cells were treated by $8 \mu \mathrm{M}$ L-685,458, $10 \mu \mathrm{M}$ XAV-939 and $80 \mu \mathrm{M}$ AG490, respectively [35]. The treatments lasted for 72 hours and the cells were observed in 12 hour intervals. The cell bearing coverslips prepared from each of the treatments were subjected to further analyses. The experiments were repeated for 3 times. 


\section{Statistical analysis}

MTT data and cell counting were evaluated with the independent-samples t-test and one-way ANOVA. Statistical significance was defined as $P<0.05$.

\section{Results}

Resveratrol caused growth arrest and apoptosis

MTT assay and viable cell counting were performed in 24 hour intervals, which revealed that resveratrol

\section{A

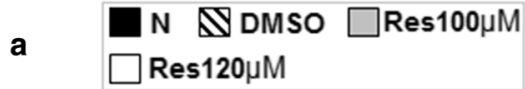

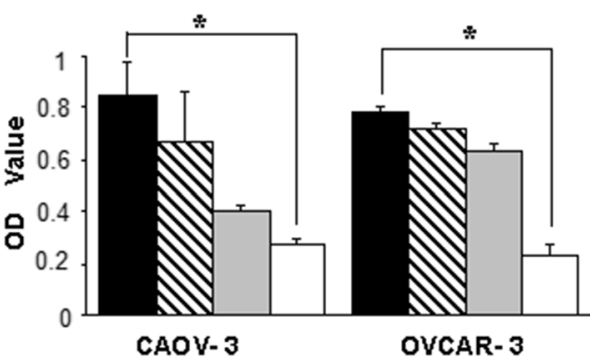

CAOV-3

B
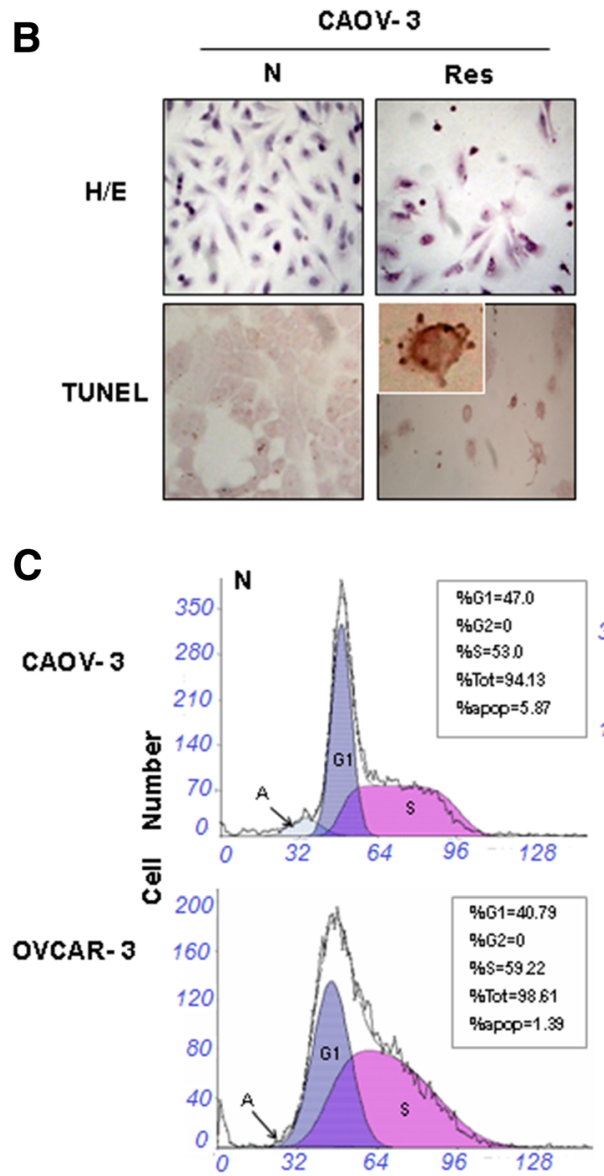
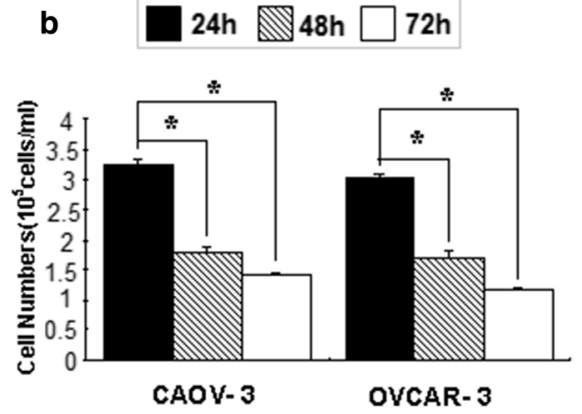

OVCAR-3
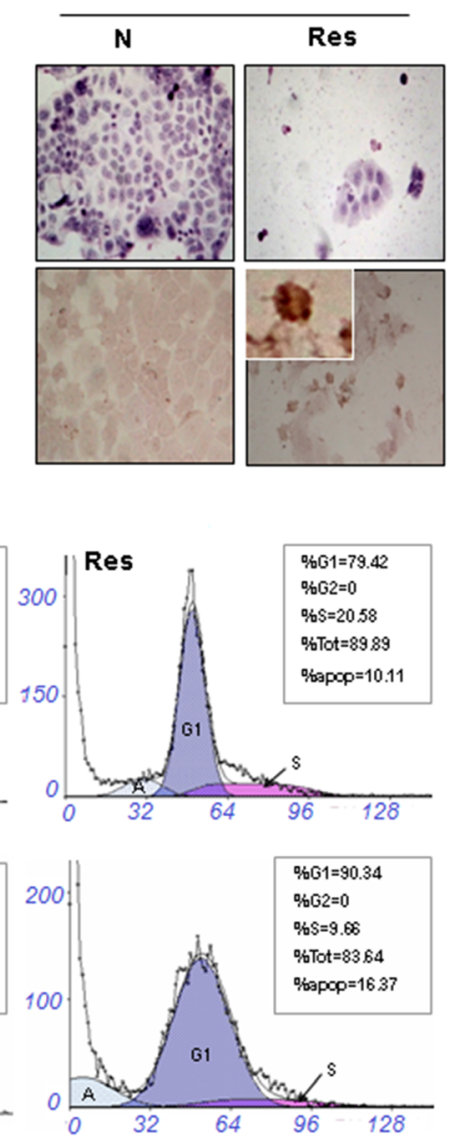

\section{DNA Content}

Figure 1 Evaluation of cellular responses of human ovarian cancer CAOV-3 and OVCAR-3 cells to $120 \mu \mathrm{M}$ resveratrol treatment. A. (a) MTT cell proliferation assay performed on the two cell lines cultured normally $(\mathrm{N})$ and incubated in 0.02\% DMSO containing medium without (DMSO) or with $100 \mu \mathrm{M}$ and $120 \mu \mathrm{M}$ resveratrol supplementation (Res) for 48 hours. *, compared with $\mathrm{N}$ group, $P<0.05$, (b) Viable cell counting of 120 $\mu \mathrm{M}$ resveratrol-treated CAOV-3 and OVCAR-3 cells at $24 \mathrm{~h}, 48 \mathrm{~h}$ and $72 \mathrm{~h}$ points. ${ }^{*}, \mathrm{P}<0.05$ in comparison with data collected at $24 \mathrm{~h}$ point. B. Hematoxylin and eosin morphological staining (H/E) and TUNEL apoptotic cell assay. C. Flow cytometry determination of cell cycle distribution and apoptosis in CAOV-3 and OVCAR-3 cells after $120 \mu \mathrm{M}$ resveratrol treatment for 48 hours. 
suppressed the growth of CAOV-3 and OVCAR-3 cells in dose- and time-related fashions and CAOV-3 cells were more sensitive to drug treatments (Figure 1A). H/E staining and TUNEL assay showed frequent apoptotic death in resveratrol-treated cell populations (Figure 1B). Flow cytometry demonstrated that $120 \mu \mathrm{M}$ resveratrol treatment caused distinct G1-phase arrest of the two OC cell lines accompanied with increased apoptotic fractions of OVCAR-3 (16.37\%) and CAOV-3 cells (10.11\%) at 48 hour time point. As shown in Figure 1C, the G1 and S fractions were $47.0 \%$ and $53.0 \%$ in normally cultured CAOV-3 cells, which changed to $79.42 \%$ and $20.58 \%$ in their resveratrol-treated counterpart. Similarly, G1 and S fractions were $40.79 \%$ and $59.22 \%$ in the normally cultured and $90.34 \%$ and $9.66 \%$ in the resveratrol-treated OVCAR-3 cells.

Differential responses of Notch1 and Notch2 to resveratrol ICC staining (Figure 2) showed that Notch1 and Notch2 as well as their downstream gene HES1 were expressed in OVCAR-3 and CAOV-3 cells; upon resveratrol treatment, Notch2 and HES1 expression were suppressed in both CAOV-3 and OVCAR-3 cells, while the expression levels of Notch1 was weakly increased in the former and decreased in the later cell line. The results of Western blotting and RT-PCR were in consistence with ICC findings in terms of down-regulated Notch2 and HES1 in both cell lines and the differential Notch1 expression in resveratrol-treated OVCAR-3 and CAOV-3 cells.

\section{Resveratrol altered $\beta$-catenin intracellular distribution patterns}

As shown in Figure 3A, Wnt2 was expressed in OVCAR-3 and $\mathrm{CAOV}-3$ cells. $\beta$-catenin proteins were distributed in both the cytoplasmic space and the nuclei of $\mathrm{CAOV}-3$, while they were mainly located in the cytoplasm of OVCAR-3 cells. After resveratrol treatment, Wnt2 was down-regulated (Figure 3B) and nuclear labeling of $\beta$-catenin became rare in CAOV-3 cells. In the case of resveratrol-treated OVCAR-3 cells, the level of Wnt2 expression remained almost
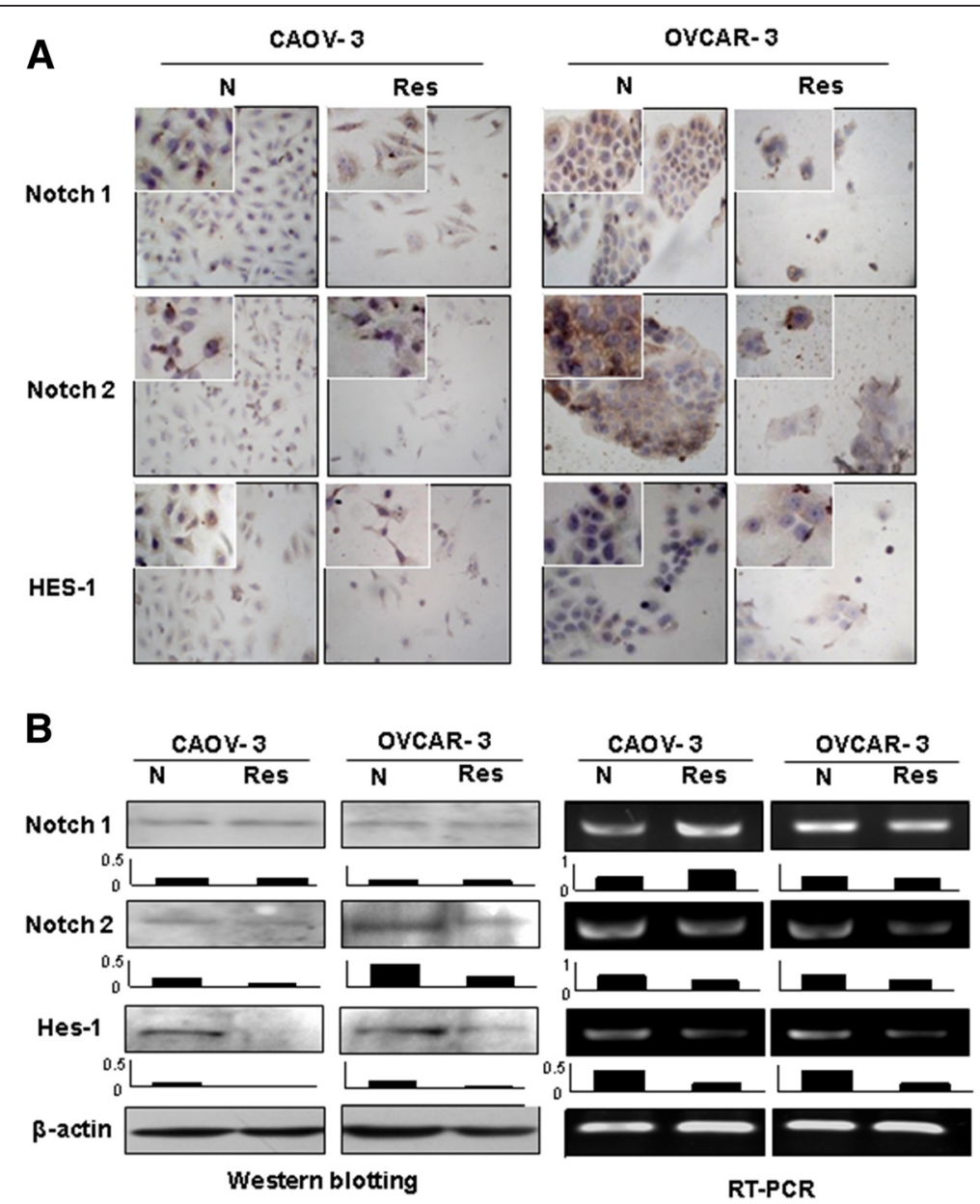

Figure 2 Examination of Notch1, Notch2 and HES1 expression in CAOV-3 and OVCAR-3 cells without ( $\mathrm{N}$ ) and with 48 hour $120 \mu \mathrm{M}$ resveratrol treatment (Res) by immunocytochemical staining (A), Western blotting and RT-PCR (B). Densitometry analyses were conducted on each of the Western and RT-PCR images. 


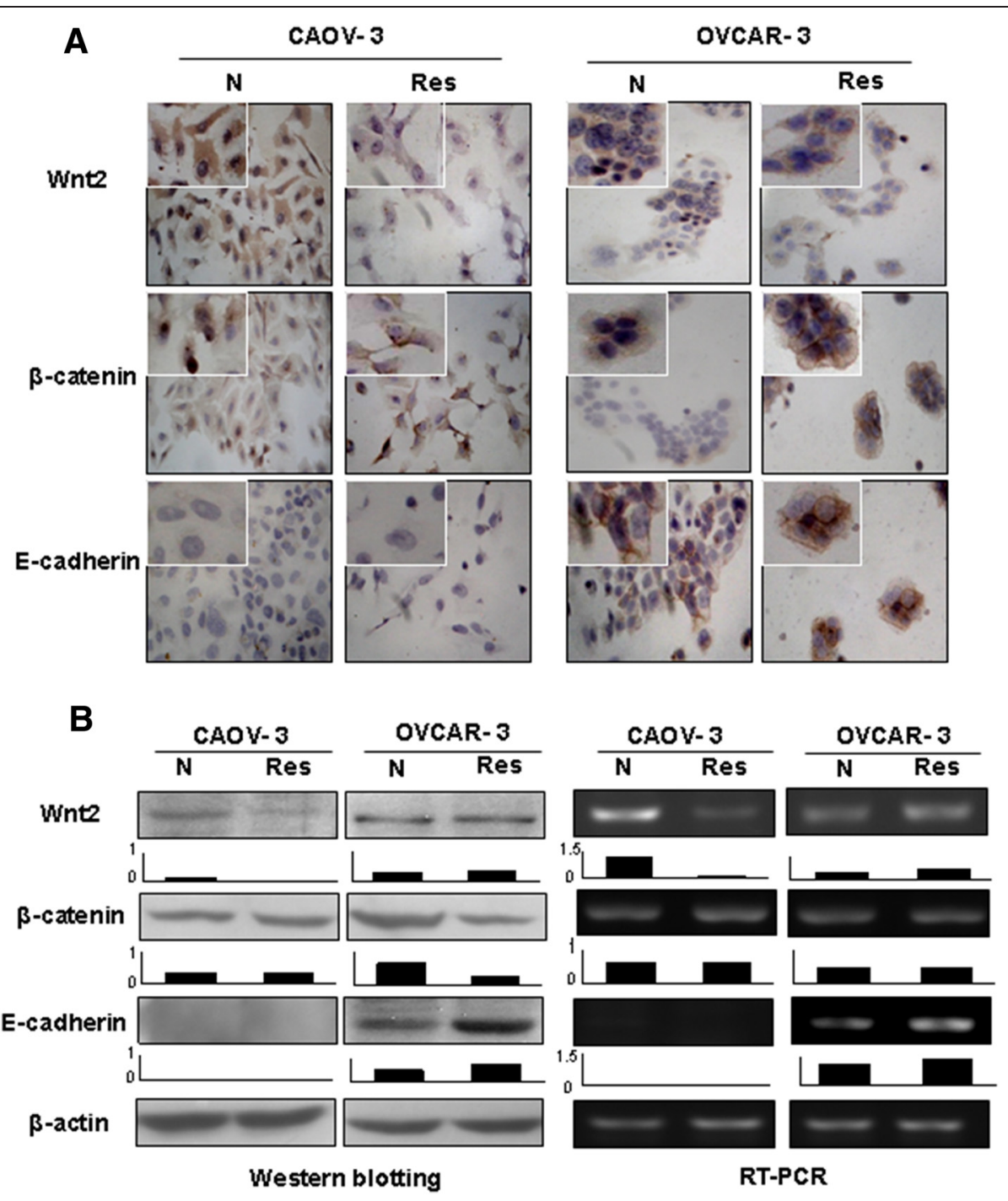

Figure 3 Examination of Wnt2, $\beta$-catenin and E-cadherin expression patterns in CAOV-3 and OVCAR-3 cells without (N) and with 48 hour $120 \mu \mathrm{M}$ resveratrol treatment (Res) by immunocytochemical staining (A), Western blotting and RT-PCR (B). Densitometry analyses were conducted on each of the Western and RT-PCR images.

unchanged, while membrane-labeling of $\beta$-catenin was clearly observed. E-cadherin, a $\beta$-catenin binding integral protein, was expressed in OVCAR-3 cells and was enhanced after resveratrol treatment; in contrast, it was undetectable in CAOV-3 cells in both RNA and protein levels irrespective to resveratrol treatment.

\section{Inhibition of STAT3 expression in resveratrol-treated OC cells}

The effects of resveratrol on STAT3 signaling in the two OC cell lines were analyzed by immunocytochemical, Western blotting and RT-PCR approaches. It was found that STAT3 was expressed in the normally cultured OVCAR-3 and CAOV-3 cells with distinct nuclear translocation (Figure 4A). STAT3 was down-regulated either in transcriptional or in translational levels in resveratrol-treated ones with reduced nuclear labeling of phosphoralated-STAT3 (Figure 4A and B). For instance, p-STAT3 was predominantly localized in the nuclei of OVCAR-3 cells and became weakened after resveratrol treatment for 48 hours.

\section{Resveratrol downregulated tumor promoter genes}

Survivin, c-Myc and Bcl-2 play active roles in cell proliferation and maintenance of ovarian cancers [36-38] and are known as the common target genes of Wnt, Notch and STAT3 signaling [17]. Therefore, their expression statuses in the two OC cell lines without and with resveratrol treatment were analyzed. As shown in Figure 5, the expression levels of c-Myc and especially survivin and Bcl-2 were decreased in both CAOV-3 


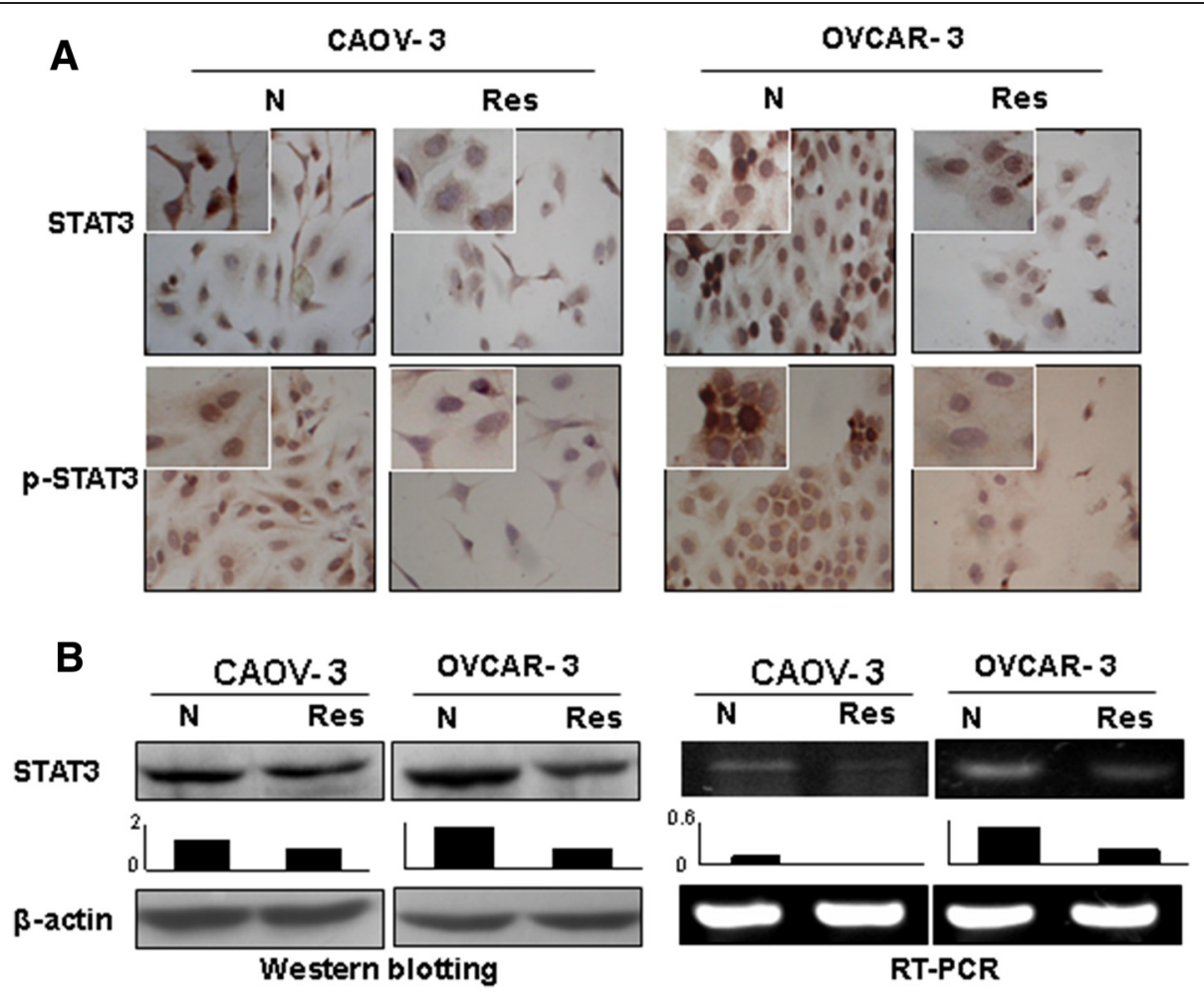

Figure 4 Effects of resveratrol on STAT signaling in ovarian cancer cells. A. Immunocytochemical illustration of the levels and intracellular distribution phosphorylated STAT3 in CAOV-3 and OVCAR-3 cells without (N) and with 48 hour $120 \mu \mathrm{M}$ resveratrol treatment (Res). B. Western blot and RT-PCR analyses of STAT3 expression levels performed in parallel with immunocytochemical staining.

and OVCAR-3 cells in comparison with their normally cultured counterparts.

\section{Different effects of selective Notch, Wnt and STAT3 inhibitors}

To evaluate potential biological significance of activated Notch, Wnt and STAT3 signaling in the two OC cells, the selective inhibitors of the three signaling pathways were used to treat OVCAR-3 and CAOV-3 cells, respectively. The results revealed that although $8 \mu \mathrm{M}$ L-685,458 blocked Notch activation in the two cell lines in terms of reduced cytoplasmic distribution and nuclear labeling of HES1 proteins, this treatment neither caused growth arrest nor cell death (Data not shown). Wnt inhibitor XAV-939-treated OVCAR-3 and CAOV-3 cells showed reduction of cytoplasmic distribution and nuclear translocation of $\beta$-catenin but no distinct morphologic change and growth inhibition could be observed in comparison with their normally cultured counterparts (Figure 6A and B). STAT3 phosphorylation was inhibited in OVCAR-3 and CAOV-3 cells upon $80 \mu \mathrm{M}$ AG490 treatment for 48 hours, accompanied with similar growth suppression rates (74\%) as that of resveratrol-treated populations (68\%) in OVCAR-3 cells and $82 \%$ versus $77 \%$ in CAOV-3 cells (Figure 6A-C).

\section{Discussion}

Ovarian cancer is one of the most lethal malignancies due to its strong spreading tendency via different dissemination routes including peritoneal implantation [6,39]. Because of the difficulty to remove cancer cells radically, adjuvant chemotherapy is employed to reduce the risk of tumor relapse [40]. Nevertheless, the therapeutic outcome of OC patients is not optimistic due to the frequent drug resistance of cancer cells and severe toxic effects of anticancer drugs [41,42]. Apparently, more effort should be made to explore safer and more effective agent for ovarian cancer patients. It has been known that the anticancer doses of resveratrol are non-toxic to some kinds of normal cells/tissues [15,43], suggesting the potential values of this compound in the treatment of human cancers. Resveratrol also exerts inhibitory effects on ovarian cancer cells $[21,22]$. The current study further demonstrates that the resveratrol sensitivities of ovarian cancer cells are not identical, because $100 \mu \mathrm{M}$ resveratrol is sufficient to cause G1 phase arrest and remarkable apoptosis in CAOV-3 while a dose of $120 \mu \mathrm{M}$ is required to induce similar cellular events in OVCAR-3 cells. Although the underlying reason(s) leading to the differential resveratrol sensitivities remains to be disclosed, our results have potential translational values because 1) both OVCAR-3 and CAOV-3 


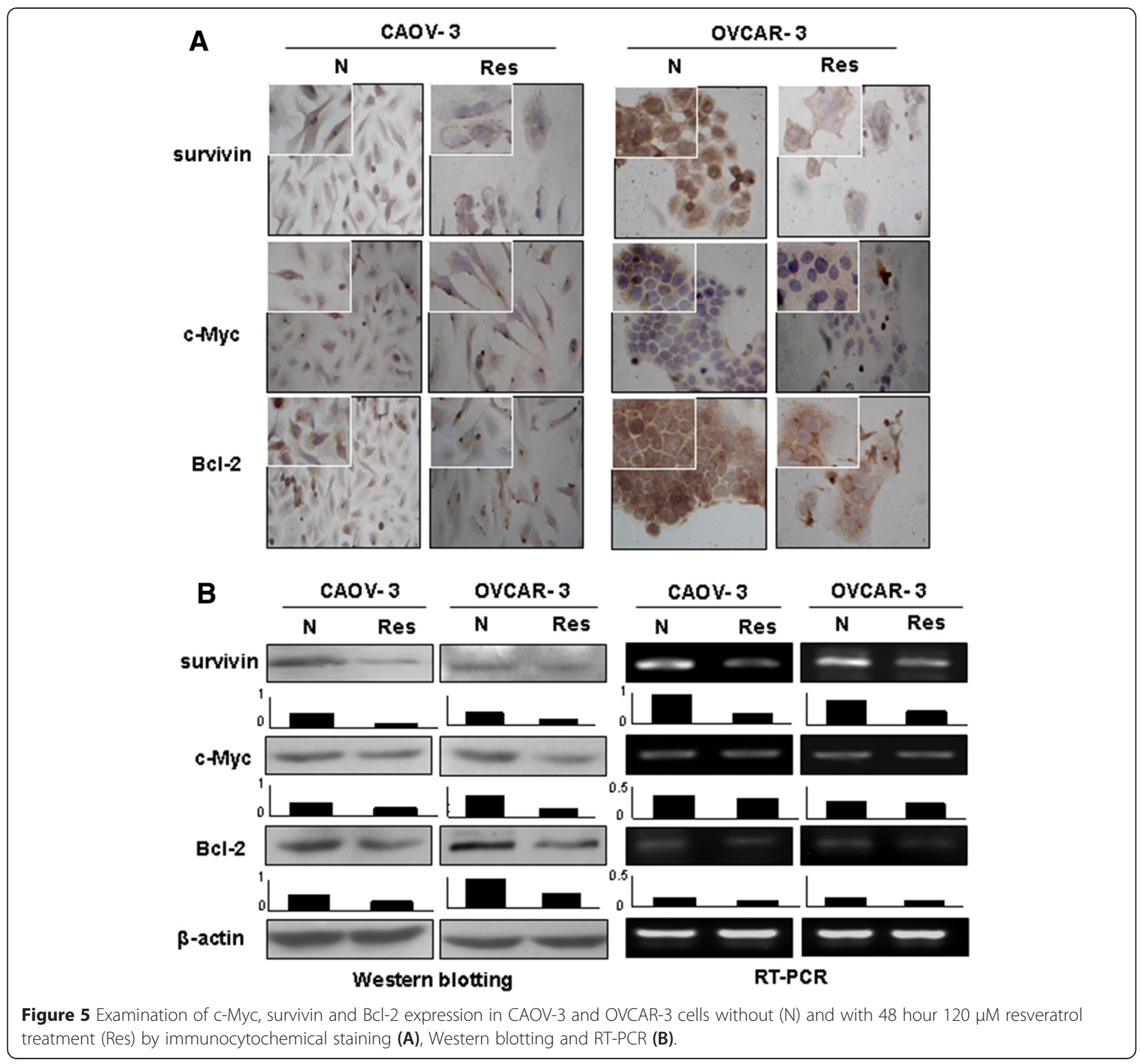

cells are resistant to cis-platinum (cis-diamminedichloroplatinum), a commonly used agent in anti-OC therapy $[43,44]$, 2) $120 \mu \mathrm{M}$ resveratrol is harmless to normal neural and urothelial cells in vivo [15,45] and 3) longterm intra peritoneal administration of $150 \mathrm{mg}$ (657 $\mu \mathrm{M}) / \mathrm{kg} /$ per day resveratrol dose not affect the life quality of the rats including the reproductive ability [Li-Xia Zhong et al. unpublished data]. In this context, it would be considered that resveratrol may be a promising candidate to treated ovarian cancers, especially those with cis-platinum resistance.

A body of evidence suggests that many molecular alterations occur during ovarian carcinogenesis, of which the activated Notch, Wnt and STAT3 signaling pathways are supposed to play active roles in the carcinogenic process by up-regulating the expression of some tumor promoting genes such as $\mathrm{c}-\mathrm{Myc}$, survivin and $\mathrm{Bcl}-2$ $[46,47]$. On the other hand, resveratrol possesses multifaceted targeting capacities $[48,49]$ and the cancer-associated signaling pathways mediated by STAT3, Wnt2 and/or Notch1/2 have been known as its molecular targets [35]. Although the inhibitory effects of resveratrol on ovarian cancer cells have been documented, the critical molecular event(s) caused by resveratrol remain largely unknown. In this study, the statuses of STAT3, Notch and Wnt2 signaling in OVCAR-3 and CAOV-3 cells and the influences of resveratrol in them are investigated. It is revealed that all of the three signaling pathways are activated in the 


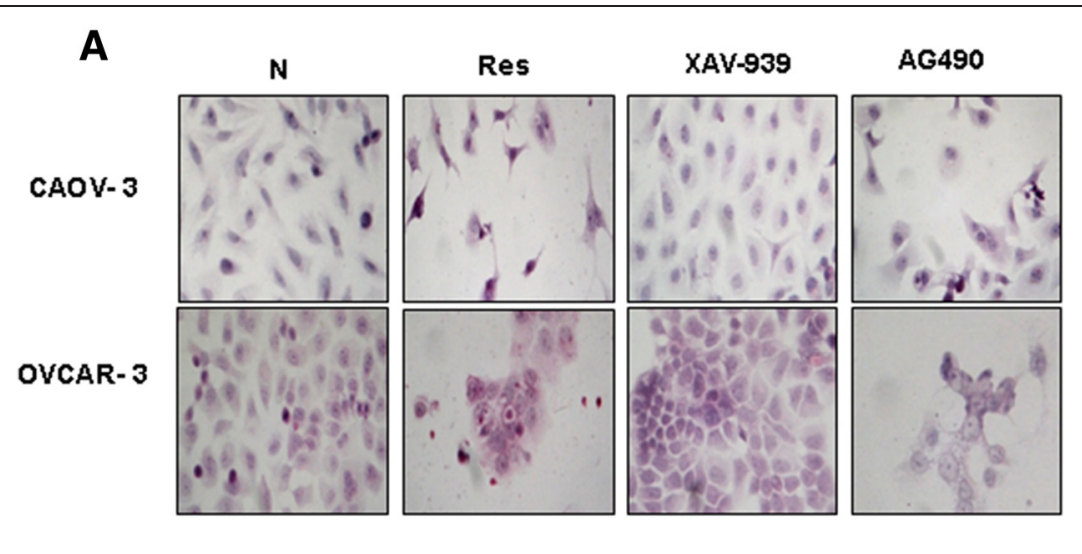

B
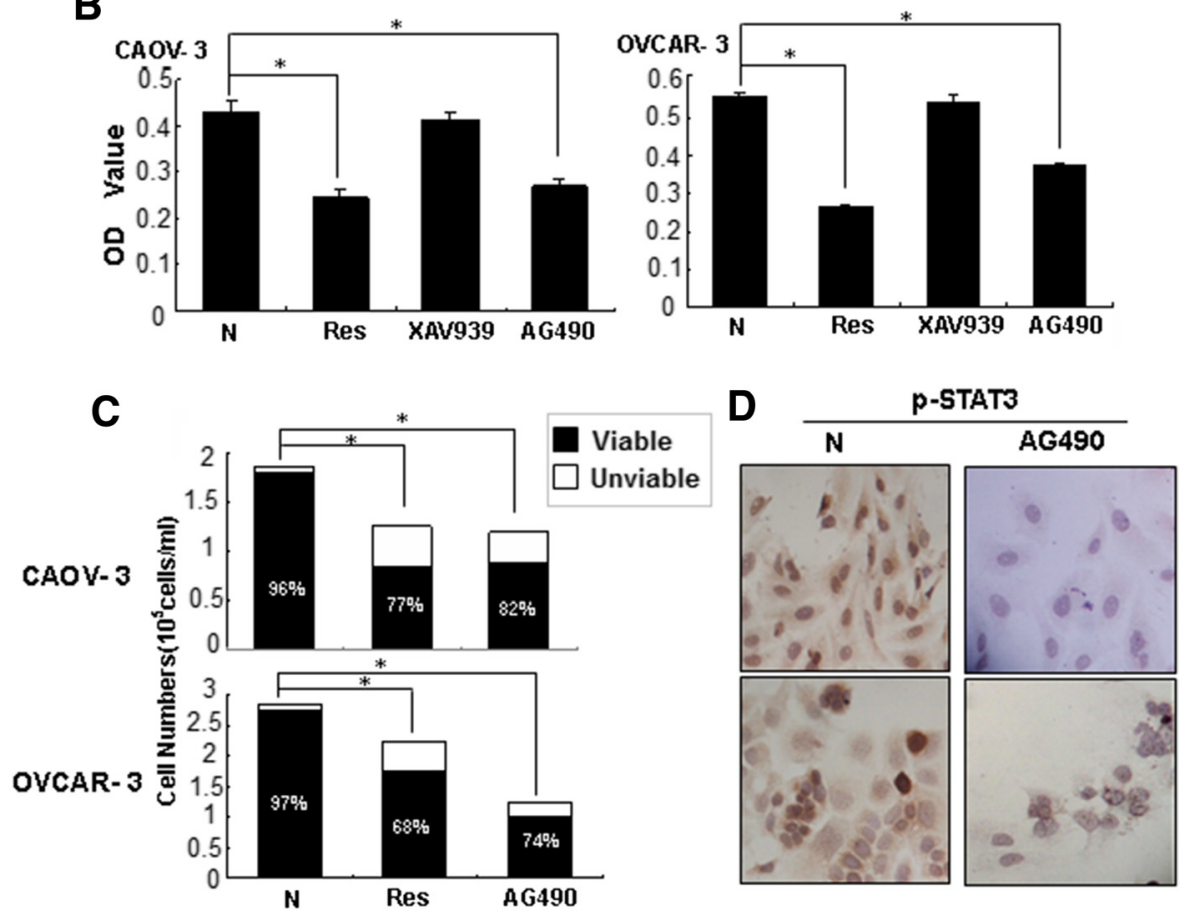

Figure 6 Demonstration of inhibitory effects of selective STAT3 inhibitor AG490 on the proliferation and STAT3 phosphorylation in CAOV-3 and OVCAR-3 cells by Hematoxylin and eosin morphological staining (A), MTT cell proliferation assay (B), viable and unviable cell counting (C) and p-STAT3 oriented immunocytochemical staining (D). Normally cultured (N), resveratrol-treated (Res) and Wnt selective inhibitor XAV939-treated cells (XAV939) were cited as normal, effective and ineffective controls, respectively.

two cell lines because of the co-existence of nuclear translocations of phosphorylated STAT3 (p-STAT3), HES1 and $\beta$-catenin. After resveratrol treatment, nuclear labeling of p-STAT3, $\beta$-catenin and HES1 become rare and weakened, indicating the concurrent inhibition of the biological activities of STAT3, Notch and Wnt2 signaling by this multi-targeting compound and its correlation with the suppressed growth of ovarian cancer cells.

c-Myc, Bcl-2 and survivin are well known cancer promoter genes and their transcription can be triggered by STAT3, Notch and Wnt signaling, respectively $[18,46,47]$. In accompany with distinct growth arrest and apoptosis, the expression of these three genes is down-regulated in resveratrol-treated OVCAR-3 and CAOV-3 cells, which may be considered as the consequence of concurrent STAT3, Notch and Wnt inactivation. It has been recognized that reduction or absence of membrane E-cadherin distribution indicates the dedifferentiation states of epithelial cells and is one of the major reasons of $\beta$-catenin cytoplasmic accumulation and nuclear translocation [50,51]. In resveratrol treated OVCAR-3 cell population, the level of E-cadherin expression is increased and more abundant $\beta$-catenin membrane distribution can be observed, indicating the favorable effects of resveratrol on cell differentiation 
and inhibitory effect on Wnt signaling. Based on this notion, the lack of membranous $\beta$-catenin labeling of resveratrol-treated CAOV-3 cells would be largely due to the silenced E-cadherin expression. Even though, CAOV-3 cells remain sensitive to resveratrol, suggesting that the presence or absence of E-cadherin expression and $\beta$-catenin nuclear translocation may not be the critical factor in determining the responsiveness of OC cells to resveratrol.

Although resveratrol suppressed STAT3, Notch and Wnt activations have been evidenced in OVCAR-3 and CAOV-3 cells, it is still unclear which of them are/is closely linked with resveratrol-caused cell crisis. To address this issue, the two ovarian cancer cells are treated by selective inhibitors of Notch, Wnt and STAT3 respectively and their responses are compared with that of their resveratroltreated and normally cultured counterparts. The results reveal that Notch inhibitor L-685,458 and Wnt inhibitor XAV-939 efficiently block nuclear translocations of HES1 and $\beta$-catenin, but neither of them leads to distinct growth inhibition of OVCAR-3 and CAOV-3 cells. On the other hand, STAT3 inhibitor AG490 suppresses proliferation and induces apoptosis in the extents as similar as that of resveratrol-treated cells. These findings thus suggest 1) the critical roles of STAT3 activation in the growth and survival of human ovarian cancer cells and 2) STAT3 signaling as the common oncotarget of resveratrol in cancer cells with different origins [52]. Although simply block of Notch or Wnt signaling transduction has little inhibitory effect on the two OC cell lines so far checked, the implications of their inactivation can not been overlooked because of their compensatory roles in regulating the expression of ovarian cancer-related genes including the ones examined in this study.

\section{Conclusion}

Our current study demonstrate the efficiencies of resveratrol in inhibiting human ovarian cancer cells in terms of remarkable G1 phase accumulation, increased apoptosis fraction and concurrent suppression of Wnt, Notch and STAT3 signaling as well as their downstream cancerrelated gene expression. Treatments with Wnt, Notch or STAT3 selective inhibitor reveal that only AG490, a JAKspecific inhibitor, inhibits OVCAR- 3 and CAOV- 3 cells in the extent as similar as that of resveratrol, suggesting the importance of STAT3 activation in the maintenance and survival of ovarian cancer cells. It is therefore possible that the activated STAT3 signaling is the critical molecular target of resveratrol and this polyphenol compound would be an alternative option in the management of ovarian cancers, especially the ones insensitive to conventional therapeutic drugs.

\section{Competing interests}

The authors declare that they have no competing interests.

\section{Authors' contributions}

ZLX carried out the analyses of cellular and molecular effects of resveratrol on ovarian cancer cells. LH participated in data analyses and morphological examination. MLW carried out cell culture and the statistical analysis. XYL participated in sample preparation for protein and RNA analyses. ZMJ carried out Western blotting and RT-PCR analyses. XYC participated in immunocytochemical staining. $J$ involved in the design of the study and performed the statistical analysis. YZ participated in the design of the study and coordination and helped to draft the manuscript. All authors read and approved the final manuscript.

\section{Acknowledgments}

This work was supported by National Key Research Fund from National Department of Science and Technology (2008ZX09101-049), the grants from National Natural Science Foundation of China (No. 81450016, 81272786, 81071971, 81072063 and 30971038), Research Fund for PhD supervisors from National Education Department of China (20122105110005), Program Fund for Liaoning Excellent Talents in University (LUQ2012078) and Program for Changjiang Scholar and Innovative Research Team in University (PCSIRT). The funders had no role in study design, data collection and analysis, decision to publish, or preparation of the manuscript.

Received: 8 January 2015 Accepted: 10 April 2015

Published online: 22 April 2015

\section{References}

1. Lowe KA, Chia VM, Taylor A, O'Malley C, Kelsh M, Mohamed M, et al. An international assessment of ovarian cancer incidence and mortality Gynecol Oncol. 2013;130:107-14.

2. Kamisha T, Woolery, Hoffman MS, Kraft J, Nicosia SV, Kumar A, et al. Urinary interleukin-1 $\beta$ levels among gynecological patients. J Ovarian Res. 2014;7(1):104.

3. Husseinzadeh N. Status of tumor markers in epithelial ovarian cancer has there been any progress? A review. Gynecol Oncol. 2011;120:152-7.

4. Takai M, Terai Y, Kawaguchi H, Ashihara K, Fujiwara S, Tanaka T, et al. The EMT (epithelial-mesenchymal-transition)-related protein expression indicates the metastatic status and prognosis in patients with ovarian cancer. J Ovarian Res. 2014;7:76.

5. Usui A, Ko SY, Barengo N, Naora H. P-cadherin promotes ovarian cancer dissemination through tumor cell aggregation and tumor-peritoneum interactions. Mol Cancer Res. 2014;12:504-13.

6. Gujar S, Dielschneider R, Clements D, Helson E, Shmulevitz M, Marcato P, et al. Multifaceted therapeutic targeting of ovarian peritoneal carcinomatosis through virus-induced immunomodulation. Mol Ther. 2013;21:338-47.

7. Signorelli M, Fruscio R, Ceppi L, Dell'anna T, Vitobello D, Chiappa V, et al. The role of pelvic and aortic lymphadenectomy at second look surgery in apparent early stage ovarian cancer after inadequate surgical staging followed by adjuvant chemotherapy. Gynecol Oncol. 2014;132:312-5.

8. Collinson F, Qian W, Fossati R, Lissoni A, Williams C, Parmar M, et al. ICON1 collaborators: optimal treatment of early-stage ovarian cancer. Ann Oncol. 2014;25:1165-71

9. Aravantinos $G$, Pectasides D. Bevacizumab in combination with chemotherapy for the treatment of advanced ovarian cancer: a systematic review. J Ovarian Res. 2014; 19;7:57.

10. Katsumata N, Yasuda M, Isonishi S, Takahashi F, Michimae H, Kimura E, et al. Long-term results of dose-dense paclitaxel and carboplatin versus conventional paclitaxel and carboplatin for treatment of advanced epithelial ovarian, fallopian tube, or primary peritoneal cancer (JGOG 3016): a randomised, controlled, open-label trial. Japanese Gynecologic Oncology Group. Lancet Oncol. 2013;14(10):1020-6.

11. Suri A, Carter EB, Horowitz N, Denslow S, Gehrig PA. Factors associated with an increased risk of recurrence in women with ovarian granulosa cell tumors. Gynecol Oncol. 2013;131:321-4.

12. Davis $\mathrm{A}$, Tinker AV, Friedlander M. "Platinum resistant" ovarian cancer: What is it, who to treat and how to measure benefit? Gynecol Oncol. 2014;133:624-31.

13. Galluzzi L, Vitale I, Michels J, Brenner C, Szabadkai G, Harel-Bellan A, et al. Systems biology of cisplatin resistance: past, present and future. Cell Death Dis. 2014;5:e1257.

14. Smoliga JM, Baur JA, Hausenblas HA. Resveratrol and health - a comprehensive review of human clinical trials. Mol Nutr Food Res. 2011;55:1129-41. 
15. Wu ML, Li H, Yu L, Chen XY, Kong QY, Song X, et al. Short-term resveratro exposure causes in vitro and in vivo growth inhibition and apoptosis of bladder cancer cells. PLOS ONE. 2014;9:e89806.

16. Shu XH, Li H, Sun Z, Wu ML, Ma JX, Wang JM, et al. Identification of metabolic pattern and bioactive form of resveratrol in human medulloblastoma cells. Biochem Pharmacol. 2010;79:1516-25.

17. Sun Z, Li H, Shu XH, Shi H, Chen XY, Kong QY, et al. Distinct sulfonation activities in resveratrol-sensitive and resveratrol-insensitive human glioblastoma cells. FEBS J. 2012;279:2381-92.

18. Yu LJ, Wu ML, Li H, Chen XY, Wang Q, Sun Y, et al. Inhibition of STAT3 expression and signaling in resveratrol-differentiated medulloblastoma cells. Neoplasia. 2008;10:736-44.

19. Zhang P, Li H, Wu ML, Chen XY, Kong QY, Wang XW, et al. c-Myc downregulation: a critical molecular event in resveratrol-induced cell cycle arrest and apoptosis of human medulloblastoma cells. J Neuro-Oncol. 2006;80:123-31.

20. Piotrowska H, Myszkowski K, Ziółkowska A, Kulcenty K, Wierzchowski M, Kaczmarek M, et al. Resveratrol analogue 3,4,4,5-tetramethoxystilbene inhibits growth, arrests cell cycle and induces apoptosis in ovarian SKOV-3 and A-2780 cancer cells. Toxicol Appl Pharmacol. 2012;263:53-60.

21. Rezk Y, Gossner G, Wahl H, Tan L, Kueck A, Opipari A, et al. Resveratrol inhibits glucose uptake and ovarian cancer growth in vivo. Gynecol Oncol. 2012;125:S139

22. Vergara D, Simeone P, Toraldo D, Del Boccio P, Vergaro V, Leporatti S, et al, Resveratrol downregulates Akt/GSK and ERK signalling pathways in OVCAR-3 ovarian cancer cells. Mol Biosyst. 2012;8:1078-87.

23. Dann JM, Sykes PH, Mason DR, Evans JJ. Regulation of vascular endothelial growth factor in endometrial tumour cells by resveratrol and EGCG. Gynecol Oncol. 2009;113:374-8.

24. Stewart J, James J, McCluggage G, McQuaid S, Boyle D, Arthur K, et al. A strong correlation between expression of Wntless and of human epidermal growth factor receptor 2 in gastric, ovarian, and breast cancers suggests a novel-signalling pathway involving NF kappa B and STAT3. Lancet. 2013;381:S106

25. Groeneweg JW, Foster R, Growdon WB, Verheijen R, Rueda BR. Notch signaling in serous ovarian cancer. J Ovarian Res. 2014;7(1):95.

26. Bodnar L, Stanczak A, Cierniak S, Smoter M, Cichowicz M, Kozlowski W, et al. Wnt/ $\beta$-catenin pathway as a potential prognostic and predictive marker in patients with advanced ovarian cancer. J Ovarian Res. 2014;7:16.

27. Yue $P$, Zhang $X$, Paladino D, Sengupta B, Ahmad S, Holloway RW, et al. Hyperactive EGF receptor, Jaks and Stat3 signaling promote enhanced colony-forming ability, motility and migration of cisplatin-resistant ovarian cancer cells. Oncogene. 2012;31:2309-22.

28. Basu M, Roy SS. Wnt/ $\beta$-catenin pathway is regulated by PITX2 homeodomain protein and thus contributes to the proliferation of human ovarian adenocarcinoma cell, SKOV-3. J Biol Chem. 2013;288:4355-67.

29. Wang Q, Li H, Liu N, Chen XY, Wu ML, Zhang KL, et al. Correlative analyses of notch signaling with resveratrol-induced differentiation and apoptosis of human medulloblastoma cells. Neurosci Lett. 2008;438:168-73.

30. Shu XH, Wang LL, Song X, Shi S, Wu ML, Gu JY, Chen XY, Kong QY, Li H, Liu J. Diffusion efficiency and bioavailability of resveratrol administered to rat brain by different routes: therapeutic implications. Neurotherapeutics. 2014. doi:10.1007/s13311-014-0334-6.

31. Buick RN, Pullano R, Trent JM. Comparative properties of five human ovarian adenocarcinoma cell lines. Cancer Res. 1985;45:3668-76.

32. Hamilton TC, Young RC, McKoy WM, Grotzinger KR, Green JA, Chu EW, et al. Characterization of a human ovarian carcinoma cell line (NIH:OVCAR-3) with androgen and estrogen receptors. Cancer Res. 1983;43:5379-89.

33. Kang JH, Lee DH, Lee JS, Kim HJ, Shin JW, Lee YH, et al. Eosinophilic differentiation is promoted by blockage of Notch signaling with a gamma-secretase inhibitor. Eur J Immunol. 2005;35:2982-90.

34. Tenbaum SP, Ordóñez-Morán P, Puig I, Chicote I, Arqués O, Landolfi S, et al. $\beta$-catenin confers resistance to PI3K and AKT inhibitors and subverts FOXO3a to promote metastasis in colon cancer. Nat Med. 2012;18:892-901.

35. Zhang $P$, Li H, Yang B, Yang F, Zhang LL, Kong QY, et al. Biologica significance and therapeutic implication of resveratrol-inhibited Wnt, Notch and STAT3 signaling in cervical cancer cells. Genes Cancer. 2014;5:154-64.

36. Gąsowska-Bodnar A, Bodnar L, Dąbek A, Cichowicz M, Jerzak M, Cierniak S, et al. Survivin expression as a prognostic factor in patients with epithelial ovarian cancer or primary peritoneal cancer treated with neoadjuvant chemotherapy. Int J Gynecol Cancer. 2014;24:687-96.
37. Anderson NS, Turner L, Livingston S, Chen R, Nicosia SV, Kruk PA. BCl-2 expression is altered with ovarian tumor progression: an immunohistochemical evaluation. J Ovarian Res. 2009;2:16.

38. Baldwin RL, Tran H, Karlan BY. Loss of c-myc repression coincides with ovarian cancer resistance to transforming growth factor beta growth arrest independent of transforming growth factor beta/Smad signaling. Cancer Res. 2003:63:1413-9.

39. Bodurka DC, Levenback C, Wolf JK, Gano J, Wharton JT, Kavanagh JJ, et al. Phase II trial of irinotecan in patients with metastatic epithelial ovarian cancer or peritoneal cancer. J Clin Oncol. 2003;21:291-7.

40. Lydiksen L, Jensen-Fangel S, Blaakaer J. Is it possible to define an optimal time for chemotherapy after surgery for ovarian cancer? Gynecol Oncol. 2014;133:454-9.

41. Zhang GN, Liu H, Huang JM, Wang L, Zhao JS, Li C, et al. TP53 K351N mutation-associated platinum resistance after neoadjuvant chemotherapy in patients with advanced ovarian cancer. Gynecol Oncol. 2014;132:752-7.

42. Kim YW, Kim EY, Jeon D, Liu JL, Kim HS, Choi JW, et al. Differential microRNA expression signatures and cell type-specific association with Taxol resistance in ovarian cancer cells. Drug Des Devel Ther. 2014;8:293-314.

43. Mujoo K, Zhang L, Klostergaard J, Donato NJ. Emergence of cisplatin-resistant cells from the OVCAR-3 ovarian carcinoma cell line with p53 mutations, altered tumorigenicity, and increased apoptotic sensitivityto p53 gene replacement. Int J Gynecol Cancer. 2000;10:105-14.

44. Tsunetoh S, Terai Y, Sasaki H, Tanabe A, Tanaka Y, Sekijima T, et al. Topotecan as a molecular targeting agent which blocks the Akt and VEGF cascade in platinum-resistant ovarian cancers. Cancer Biol Ther. 2010;10:1137-46.

45. Shu XH, Li H, Sun XX, Wang Q, Sun Z, Wu ML, et al. Metabolic patternsand biotransformation activities of resveratrol in human glioblastoma cells: relevance with therapeutic efficacies. PLOS ONE. 2011;6:e27484.

46. Reya T, Clevers H. Wnt signalling in stem cells and cancer. Nature. 2005;434:843-50.

47. Yuan ZL, Guan YJ, Chatterjee D, Chin YE. Stat3 dimerization regulated by reversible acetylation of asingle lysine residue. Science. 2005;307:269-73.

48. Widlund AL, Baur JA, Vang O. mTOR: more targets of resveratrol? Expert Rev Mol Med. 2013;15:e10.

49. Sato A, Okada M, Shibuya K, Watanabe E, Seino S, Suzuki K, et al. Resveratrol promotes proteasome-dependent degradation of Nanog via p53 activation and induces differentiation of glioma stem cells. Stem Cell Res. 2013;11:601-10.

50. Hazan RB, Norton L. The epidermal growth factor receptor modulates the interaction of E-cadherin with the actin cytoskeleton. J Biol Chem. 1998;273:9078-84

51. Wu C, Cipollone J, Maines-Bandiera S, Tan C, Karsan A, Auersperg N, et al. The morphogenic function of E-cadherin-mediated adherens junctions in epithelial ovarian carcinoma formation and progression. Differentiation. 2008;76:193-205.

52. Harikumar KB, Aggarwal BB. Resveratrol: a multitargeted agent for age-associated chronic diseases. Cell Cycle. 2008;7:1020-35.

53. Satoh J, Kuroda Y. $\beta$-catenin expression in human neural cell lines following exposure to cytokines and growth factors. Neuropathology. 2000;20:113-23.

54. Thomadaki H, Scorilas A. Breast cancer cells response to the antineoplastic agents cisplatin, carboplatin, and doxorubicin at the mRNA expression levels of distinct apoptosis-related genes, including the new member, BCL2L12. Ann N Y Acad Sci. 2007;1095:35-44.

\section{Submit your next manuscript to BioMed Central and take full advantage of:}

- Convenient online submission

- Thorough peer review

- No space constraints or color figure charges

- Immediate publication on acceptance

- Inclusion in PubMed, CAS, Scopus and Google Scholar

- Research which is freely available for redistribution 